\title{
THE DEVELOPMENT OF GLIBENCLAMIDE-SACCHARIN COCRYSTAL TABLET FORMULATIONS TO INCREASE THE DISSOLUTION RATE OF THE DRUG
}

\author{
ARIF BUDIMAN*, PATIHUL HUSNI, SHAFIRA, TAZYINUL Q. ALFAUZIAH
}

Department of Pharmaceutics and Pharmaceutical Technology, Faculty of Pharmacy, Universitas Padjadjaran, Jatinangor 45363, Indonesia

Email: arif.budiman@unpad.ac.id

Received: 29 Apr 2019, Revised and Accepted: 01 Jun 2019

\section{ABSTRACT}

Objective: Cocrystallisation is a promising method in order to increase the solubility and dissolution of poorly water-soluble drugs. The aim of this study was to prepare, formulate and evaluate glibenclamide (GCM) cocrystal in direct compress tablet dosage form using saccharin (SAC) as the coformer.

Methods: GCM cocrystal with various stoichiometric ratios were prepared by the solvent drop grinding method. The co-crystal was characterized by a saturated solubility test and dissolution rate test, Fourier Transform Infrared Spectroscopy (FTIR), Differential Scanning Calorimetry (DSC), and Powder X-Ray Diffraction (PXRD). The tablet dosage form of GCM was formulated and evaluated compare with the conventional dosage form.

Results: The solubility and dissolution rate of GCM-SAC cocrystals increased significantly compared with pure GCM, especially for ratio of $1: 2$. The dissolution rate of cocrystal with ratio 1:2 increased by almost $91.9 \%$ compared with pure GCM. Based on the FTIR analysis, it showed the shifting of characteristic bands of GCM in the spectrum and there was no chemical reaction in GCM cocrystal. In PXRD measurement, the new crystalline peak was detected in the crystal habit of cocrystal compared with pure GCM and coformer. The new single melting of GCM-SAC cocrystal also was detected in DSC measurement. The tablets of GCM-SAC cocrystal were successfully prepared by direct compression method which rapidly disintegrated ( $1 \mathrm{~min}$ ) and has higher dissolution compared with its pure form (32.36\% greater than glibenclamide after 45 min).

Conclusion: The tablet dosage form of GCM cocrystal with SAC as coformer was successfully prepared, formulated and improved its solubility and dissolution rate.

Keywords: Cocrystal, Tablet, Glibenclamide, Saccharin, Dissolution

(C) 2019 The Authors. Published by Innovare Academic Sciences Pvt Ltd. This is an open access article under the CC BY license (http://creativecommons.org/licenses/by/4.0/) DOI: http://dx.doi.org/10.22159/ijap.2019v11i4.33802

\section{INTRODUCTION}

Solubility and dissolution are important factors in the pharmacological effect of the drug [1]. Although the level of drug solubility is needed for oral absorption, almost $40 \%$ of the drug in the market shows low solubility in water. Due to the low solubility, the drug is absorbed slowly and the levels of the drug in the blood are lower than the required [2, 3]. In the biopharmaceutical classification system (BCS), glibenclamide (GCM) is included in class II, which means it has high permeability and low solubility. GCM is a type 2 antidiabetic drug used for controlling glycemia [4]. Glibenclamide has a low solubility of about $4 \mathrm{mg} / \mathrm{l}$ [5] and its bioavailability is only $40-45 \%$.

Several studies have been reported about methods improving glibenclamide solubility such as fast dissolving tablet (FDT) [6], lipid nanocrystal [7], nanoparticles [8, 9], solid dispersion [10, 11], selfemulsifying drug delivery systems (SEEDS) [12] and liquisolid technology [13]. Cocrystal is one method that can increase the solubility of the API [14]. Cocrystal can be defined as complex crystal formations with stoichiometric multi-component system connected by a synthon that in pharmaceutical crystal engineering is called "a non-covalent interaction involving hydrogen bonds, in which two distinct components are solid under ambient conditions". The previous study showed that cocrystallization method can increase the solubility of GCM compared with pure GCM with saccharin and aspartame as the coformer $[14,15]$.

In this study, glibenclamide cocrystal was prepared by solvent drop grinding using saccharin as the coformer. Saccharin (SAC) is an artificial sweetener that commonly used in cocrystallization as the coformer. Some several studies reported that using SAC as coformer can increase the solubility of carbamazepine, ketoprofen and GCM compared with pure drugs [14, 16, 17]. In the last decades, the research of cocrystal has grown rapidly, but only a few research conduct about the preparation and evaluation of cocrystal in the tablet dosage form. Thus, the aim of this study was to prepare, formulate and evaluate GCM cocrystal in tablet dosage form using SAC as the coformer. The tablet formulation was designed as direct compress tablet to minimize manufacturing process impact to GCM cocrystal performance.

\section{MATERIALS AND METHODS}

\section{Materials}

GCM was obtained from Indofarma (Indonesia) with a purity $>99 \%$ and SAC and ethanol pro analysis were obtained from Merck (Germany).

\section{Preparation of cocrystal}

The cocrystal of GCM-SAC was employed with solvent drop grinding method. GCM and SAC were weighted and mixed with different molar ratio (1:1, 1:2 and 2:1). The mixture was ground by mortar and pestle, during grinding add ethanol as a solvent for $15 \mathrm{~min}$. The mixture was dried overnight at ambient temperature.

Solubility study

The sample equivalent to $20 \mathrm{mg} \mathrm{GCM}$ was placed in vials containing water. The vials were agitated using a mechanical agitator at room temperature and allowed to stand for equilibrations for 24 and $48 \mathrm{~h}$. The samples were filtered through a $0.45 \mu \mathrm{m}$ membrane filter, diluted with distilled water and analyzed spectrophotometrically at $266 \mathrm{~nm}$ [15].

\section{Particulate dissolution study}

Dissolution studies of cocrystals were performed using type 2 apparatus (paddle). A sample of cocrystals weighed in equal to 50 mg GCM then put into $900 \mathrm{ml}$ buffer phosphate pH 8 and stirred at $75 \mathrm{rpm}$, the temperature was maintained at $37 \pm 0.2^{\circ} \mathrm{C}$. The $5 \mathrm{ml}$ of samples were filtered through a syringe filter of $0.45 \mu \mathrm{m}$ pore size periodically (at $0,10,15,30,45$, and $60 \mathrm{~min}$ ) and analyzed by UV spectrophotometer at $266 \mathrm{~nm}$ [15].

\section{Characterization of cocrystal}

FTIR analysis

FTIR analysis was employed to evaluate the interaction between drug and coformer. The cocrystal was dispersed homogeneously in $\mathrm{KBr}$ pellet. The samples were analyzed using an infrared spectrophotometer $\left(\right.$ Shimadzu $\left.{ }^{\circledR}\right)$ at room temperature in a range of wavenumbers from $400-4000 \mathrm{~cm}^{-1}$ [18] 


\section{Powder X-ray diffractometer (PXRD)}

The X-ray generator was operated using Phillip PW 1835 at $40 \mathrm{kV}$ and $40 \mathrm{~mA}$ using $\mathrm{CuK} \alpha$ radiation. The scans were performed between $3{ }^{\circ}$ and $40^{\circ}$ with a scanning rate of $4 \% \mathrm{~min}$ at room temperature [14].

\section{Differential scanning calorimetry (DSC)}

DSC analysis was performed using Linseis DSC PT1000. Approximately $5 \mathrm{mg}$ of the powder sample was placed in an aluminum pan and heated at a rate of $10^{\circ} \mathrm{C} / \mathrm{min}$, from 0 to $300^{\circ} \mathrm{C}$ temperature range, under nitrogen stream $[19,20]$.

\section{Formulation of cocrystal tablet}

An accurately weighed quantity of cocrystal equivalent to drug dose (5 mg) and all other ingredients was mixed. The mixture was directly compressed into tablets. Round concave tablets of $100 \mathrm{mg}$ mass were obtained [21]. Table 1 outlines the composition of tablet formulations.

Table 1: Formulation of cocrystal tablet

\begin{tabular}{llll}
\hline Ingredients & Amount (mg/tablet) & & F2 (1:2) \\
\cline { 2 - 4 } & F1 (1:1) & 5 & \\
\hline Cocrystals & 5 & 0.5 & \\
Mg stearate & 0.5 & & \\
Ludipress & Add up to 100 & & \\
\hline
\end{tabular}

\section{Evaluation of cocrystal powder (pre-compression parameters)}

The mixture of drug and excipient were evaluated for tapped density, bulk density, and flow properties and compressibility parameters. Flow properties of powder were determined by the angle of repose and compressibility by Carr's index [22, 23].

\section{Evaluation of cocrystal tablet (post-compression parameters)}

\section{The thickness and weight variation}

Twenty tablets were randomly taken from each formulation and thickness was measured using Vernier caliper. The results are expressed as mean \pm standard deviation (SD). The average weight of twenty tablets was determined using an electronic balance and tablet were weighed individually and compared to average weight.

\section{Hardness test}

Ten tablets were randomly selected from each batch and hardness of tablets was determined by using hardness tester. The mean values and standard deviation for each batch were calculated [24].

\section{Friability test}

The friability of tablets was measured using friability tester. Twenty tablets were placed in plastic friability tester attached to motor revolving at a speed of $25 \mathrm{rpm}$ for $4 \mathrm{~min}$. The tablets were then deducted, reweighed, and percent weight loss was calculated using the formula,

$\%$ friability $=(($ initial weight - final weight $) /$ initial weight $) \times 100$ [23] .

\section{In vitro disintegration time}

Determination in vitro disintegration time (DT) using distilled water at $37 \pm 2{ }^{\circ} \mathrm{C}$. The time when the tablets were disintegrated completely without any residue remaining in the apparatus was recorded as mean \pm SD [24].

\section{In vitro dissolution study}

Dissolution test of tablet glibenclamide cocrystal was performed using type 2 apparatus (paddle type). A sample tablet put into $900 \mathrm{ml}$ buffer phosphate pH 8 and stirred at $100 \mathrm{rpm}$, temperature $37 \pm 0.2{ }^{\circ} \mathrm{C}$. Sampling (5 ml) until $60 \mathrm{~min}$ at predetermined interval times $(5,10$, $15,30,45,60 \mathrm{~min}$ ) and $5 \mathrm{ml}$ of fresh medium was added after each sampling. The sample was analyzed using a UV Spectrophotometer to quantify the amount of dissolved GCM concentration [25].

\section{RESULTS AND DISCUSSION}

\section{Preparation of cocrystal}

The preparation of the GCM and SAC cocrystal was carried out by solvent drop grinding (SDG). The SDG method is reliable in the discovery of new cocrystals because the presence of a solvent can improve the rate of cocrystal formation and is suitable for cocrystal constituents with the equimolar ratio [26]. By grinding with minimal addition the solvent, the SDG can control over the polymorphic outcome of cocrystal [27]. In this experiment, saccharin was chosen as the coformer because of its stability, polarity, and ability to form a heterosynthon in cocrystal [2]. The purpose of using this method is to demonstrate an 'environmentally friendly' method of generating GCM-SAC cocrystals [28].

\section{Solubility test}

Based on fig. 1, the solubility of cocrystal (1:2) was higher than the solubility of its pure form and other cocrystals (1:1 and 2:1) for 24 and $48 \mathrm{~h}$. This indicated that the molecular interaction between GCM with SAC has successfully occured and can form a cocrystals state [25]. The interaction between hydrogen atoms of the amide groups from GCM and oxygen atoms of sulfonyl from SAC might have formed the hydrogen bonds [15]. Saccharin has a strong hydrogen bond acceptor $(\mathrm{C}=\mathrm{O})$ and strong donors $(\mathrm{N}-\mathrm{H})$ to form a robust homodimer synthon in the crystal structure with GCM [28]. In addition, the higher hydrophilicity of coformer tend to ease the solubilization process of compound [29].

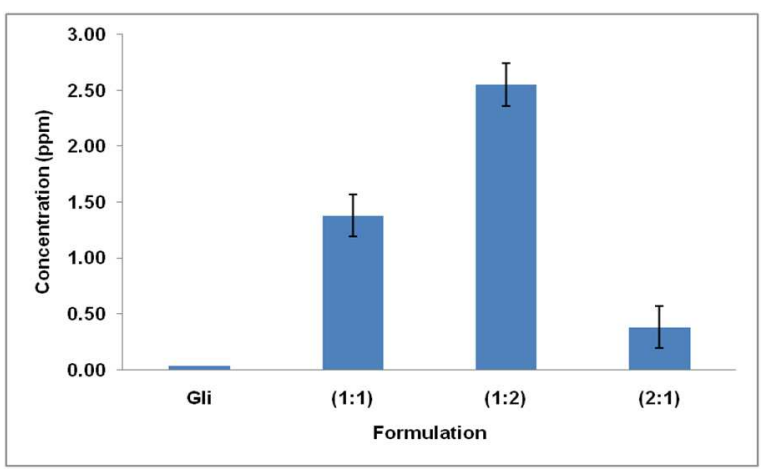

(a)

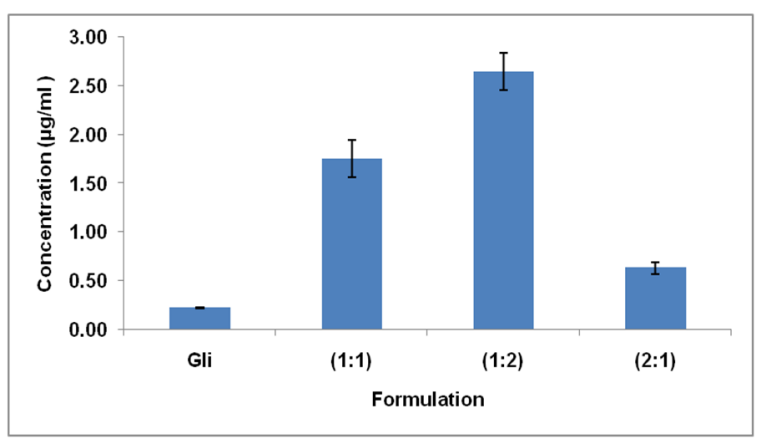

(b)

Fig. 1: The result of the solubility study of the cocrystal (a) $24 \mathrm{~h}$ (b) $48 \mathrm{~h}$ (All the values were calculated as mean \pm SD) 


\section{Particulate dissolution test}

Based on fig. 2, the dissolution rate of cocrystal was higher than its pure form. In this study, pure GCM dissolved $32.30 \pm 0.21 \%$ in $60 \mathrm{~min}$. However, the cocrystal with ratio $1: 1,1: 2$, and $2: 1$ dissolved $45.11 \pm 2.39 \%, 61.99 \pm 2.15 \%$, and $41.73 \pm 2.39 \%$ in 60 min respectively.
It is assumed that the GCM cocrystal has a weaker crystalline structure that can increase the dissolution rate of GCM. Moreover, the changed crystallinity pattern, crystal habit, size and shape of cocrystal can be attributed to increasing dissolution of GCM [25]. Increasing the dissolution rate is related to the diffusion constant, the function of the surface area, boundary-layer thickness, and solubility [26].

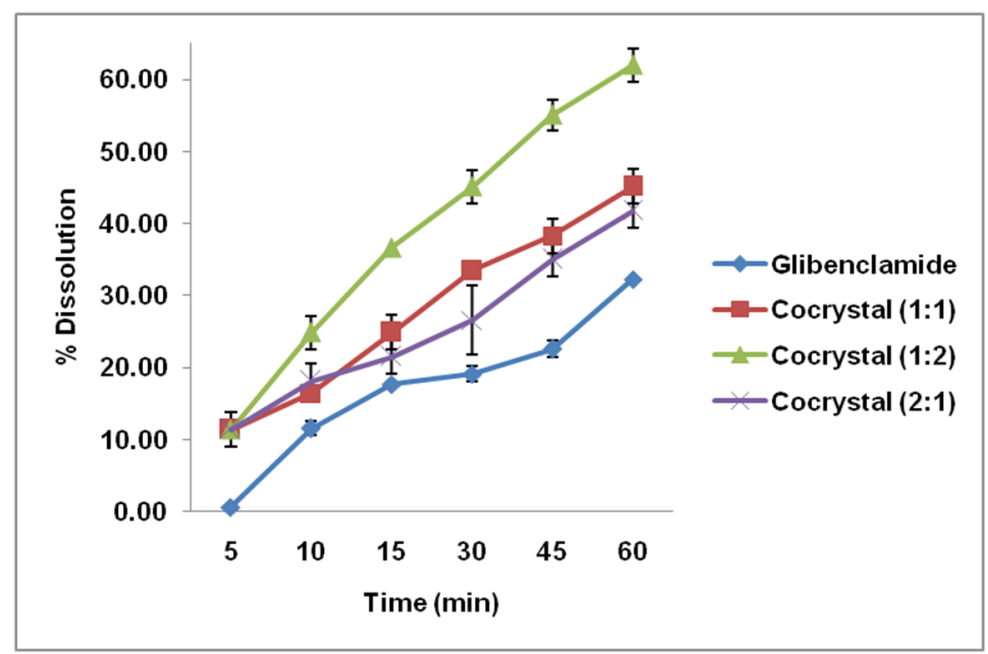

Fig. 2: In vitro dissolution study of the cocrystal (All the values were calculated as mean \pm SD)

\section{Characterization of co-crystal}

FTIR analysis

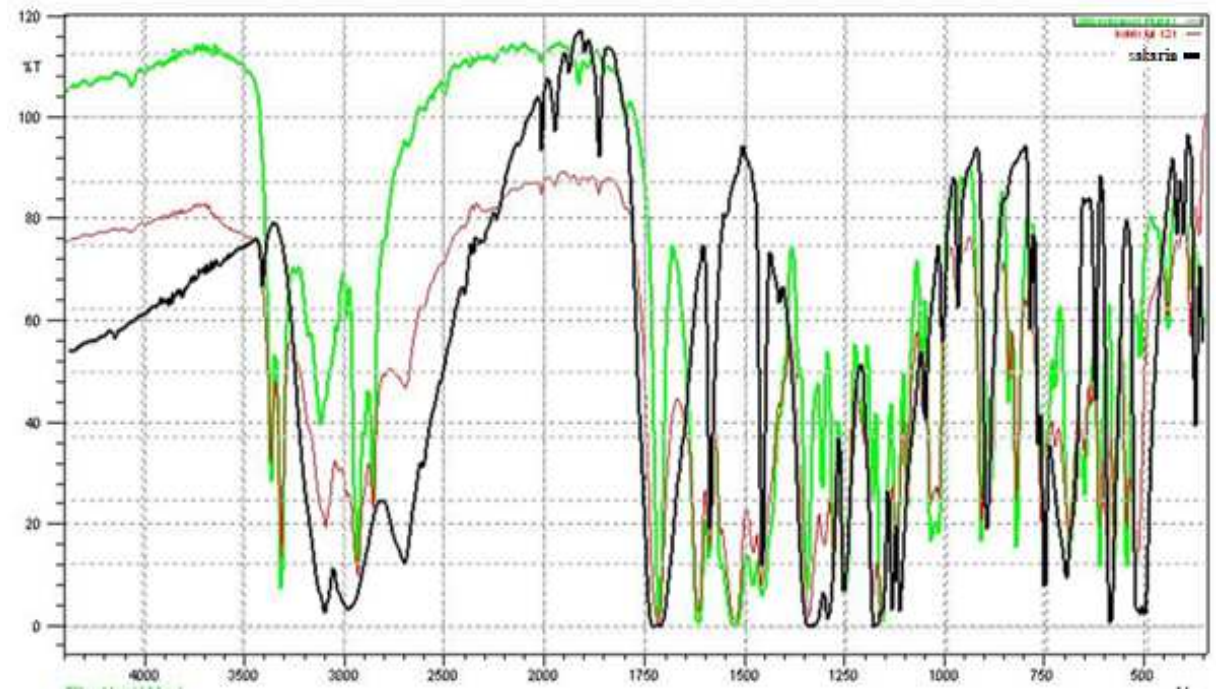

Fig. 3: Overlay Infrared spectrum of pure glibenclamide (green line), saccharin (black line), and glibenclamide-saccharin cocrystal (red line)

The weakened $\mathrm{C}=\mathrm{O}$ peak could confirm hydrogen bond formation between GCM and SAC (table 2). Interaction of GCM and SAC was predicted between amide groups of glibenclamide and sulfonyl group of saccharin [14]. In FTIR analysis, there were no new peaks observed, indicating that no chemical reaction occurred during cocrystal preparation.

Table 2: The characteristic peak of infrared

\begin{tabular}{|c|c|c|c|}
\hline \multirow{2}{*}{ Functional group } & \multicolumn{3}{|c|}{ Wavenumber $\left(\mathrm{cm}^{-1}\right)$} \\
\hline & Glibenclamide & Saccharin & Cocrystal \\
\hline \multirow[t]{2}{*}{ N-H stretch } & 3367.71 & 3398.57 & 3367.71 \\
\hline & 3313.71 & & 3313.71 \\
\hline $\mathrm{O}$-H stretch & 3116.97 & 3093.82 & 3093.82 \\
\hline \multirow{2}{*}{ C-H stretch } & 2931.80 & 2974.23 & 2931.80 \\
\hline & 2854.65 & & 2854.65 \\
\hline $\mathrm{C}=0$ stretch & 1716.65 & 1724.36 & 1728.22 \\
\hline $\mathrm{C}=\mathrm{C}$ stretch & 1616.35 & & 1616.35 \\
\hline
\end{tabular}




\section{Powder X-ray diffraction}

PXRD was performed to verify the formation of the cocrystal of GCM. All crystal forms of a compound show the characteristic on diffractogram pattern of drug [26]. The overlay of the diffractogram showed peaks and intensity at an angle of $2 \theta$ of pure GCM is $10.7^{\circ}$, $12.3^{\circ}, 19.5^{\circ}, 19.8^{\circ}, 20.9^{\circ}, 22.1^{\circ}$ and intensity at an angle of $2 \theta$ of SAC is $9.01^{\circ}, 15.2^{\circ}, 19^{\circ}$, dan $24^{\circ}$. A different powder X-ray pattern for the GCM-SAC cocrystals from those of the constituent GCM and saccharin confirms the formation of a new cocrystal phase [28].

\section{Differential scanning calorimetry (DSC)}

DSC studies are performed to observe the solid-state interaction of two compounds or more by giving heat energy to the co-crystals to evaluate thermodynamic changes (endothermic or exothermic peaks) [26]. The thermogram fig. 5 showed that the melting point of cocrystal $\left(144.5-166.9^{\circ} \mathrm{C}\right)$ was lower than pure GCM (169.6-185.1 ${ }^{\circ} \mathrm{C}$ ). The change in thermal properties (melting point) indicated as evidence for the formation of cocrystal. A decrease in the melting point of the cocrystal directly correlates with increased solubility of GCM in the cocrystal system [26].

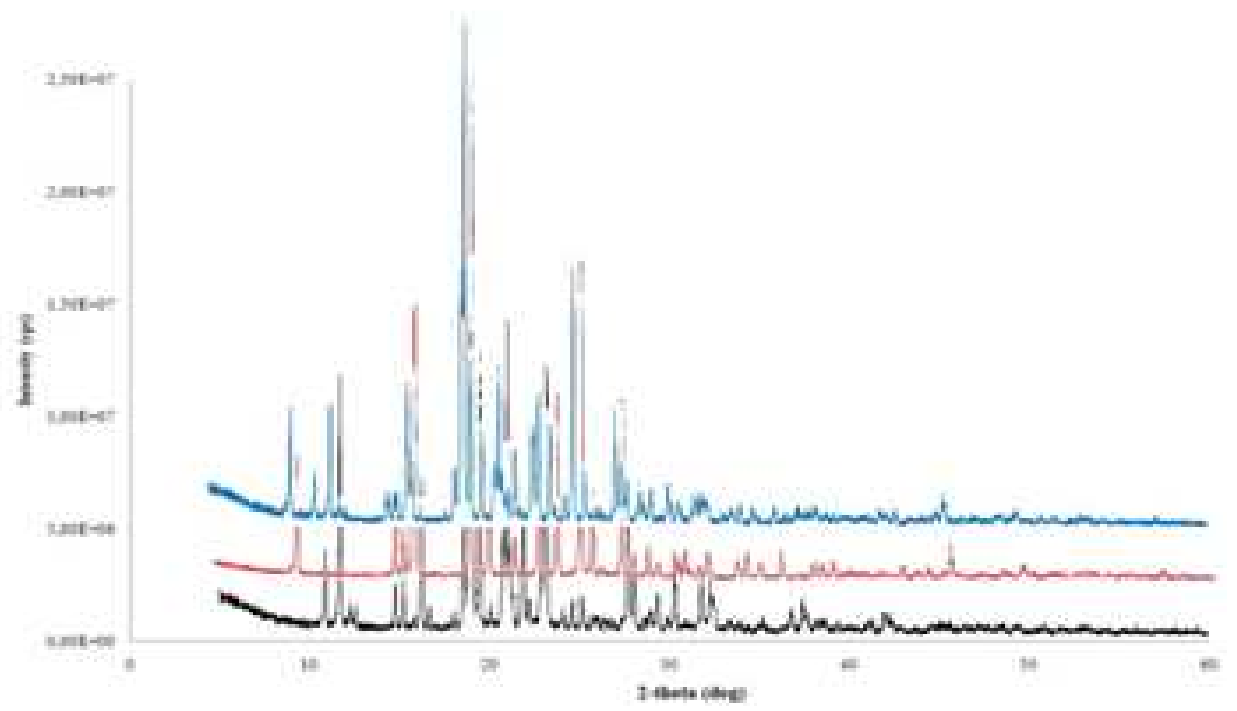

Fig. 4: Diffractogram of glibenclamide, saccharin, and cocrystal

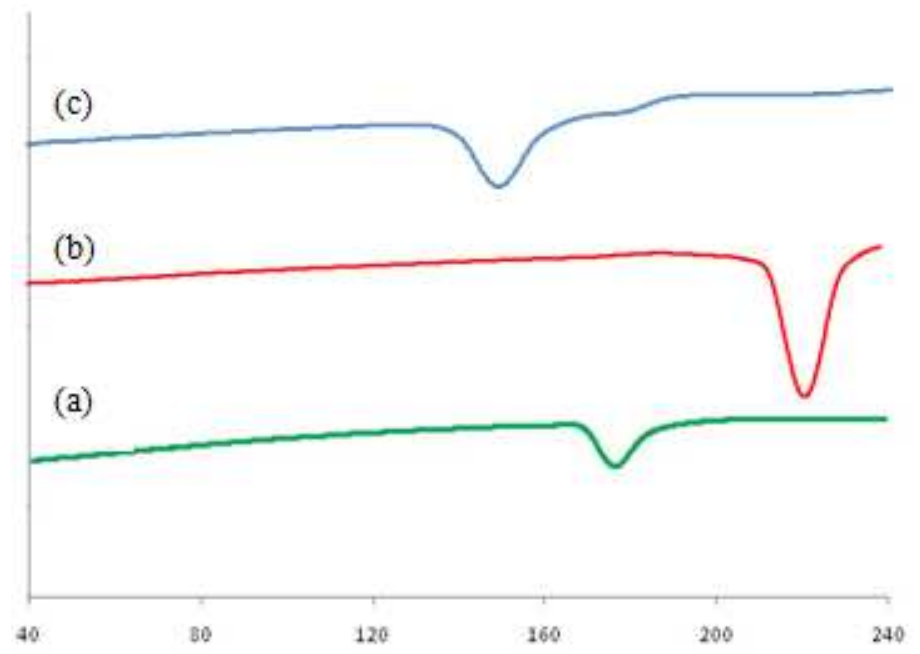

Fig. 5: Thermogram of glibenclamide (a), Saccharin (b), and Cocrystal (c)

Table 3: Evaluation of pre-compression

\begin{tabular}{llll}
\hline Parameters & F1 (1:1) & F2 (1:2) & F3 (2:1) \\
\hline Angle of repose $\left({ }^{\circ}\right)$ & 15.94 & 15.94 & 15.94 \\
Bulk density $(\mathrm{g} / \mathrm{ml})$ & 0.56 & 0.56 & 0.56 \\
Tapp density $(\mathrm{g} / \mathrm{ml})$ & 0.64 & 0.64 & 0.64 \\
Index Carr $(\%)$ & 11.27 & 11.27 & 11.27 \\
\hline
\end{tabular}

\section{Evaluation pre-compression and post-compression}

The bulk density of all the formulations was found to $0.56 \mathrm{~g} / \mathrm{ml}$, tapped density was $0.64 \mathrm{~g} / \mathrm{ml}$, angle of repose $15.94^{\circ}$, and index carr was $11.27 \%$ indicating good flow property of tablet granules and tablet of cocrystal could be compressed directly. Results of postcompression such as weight variation, diameter, thickness, hardness, friability, and disintegration time are reported in table 4 These evaluations indicated that the stoichiometry ratio of cocrystal was not affected mechanical properties of GCM. 
Table 4: Evaluation of post-compression (All the values were calculated as mean \pm SD)

\begin{tabular}{|c|c|c|c|c|c|c|}
\hline Formulation & Weight variation (mg) & Diameter (mm) & Thickness (mm) & Hardness (N) & Friability (\%) & Disintegration time (min) \\
\hline $\mathrm{F} 1(1: 1)$ & $102.80 \pm 1.11$ & $0.62 \pm 0.005$ & $0.31 \pm 0.005$ & $37.50 \pm 2.56$ & $0.96 \pm 0.01$ & $1.20 \pm 0.05$ \\
\hline F2 (1:2) & $103.15 \pm 0.93$ & $0.61 \pm 0.006$ & $0.31 \pm 0.005$ & $37.75 \pm 2.49$ & $0.96 \pm 0.02$ & $1.30 \pm 0.06$ \\
\hline F3 (2:1) & $102.95 \pm 1.00$ & $0.62 \pm 0.005$ & $0.31 \pm 0.006$ & $38.00 \pm 2.45$ & $0.97 \pm 0.01$ & $1.20 \pm 0.06$ \\
\hline
\end{tabular}

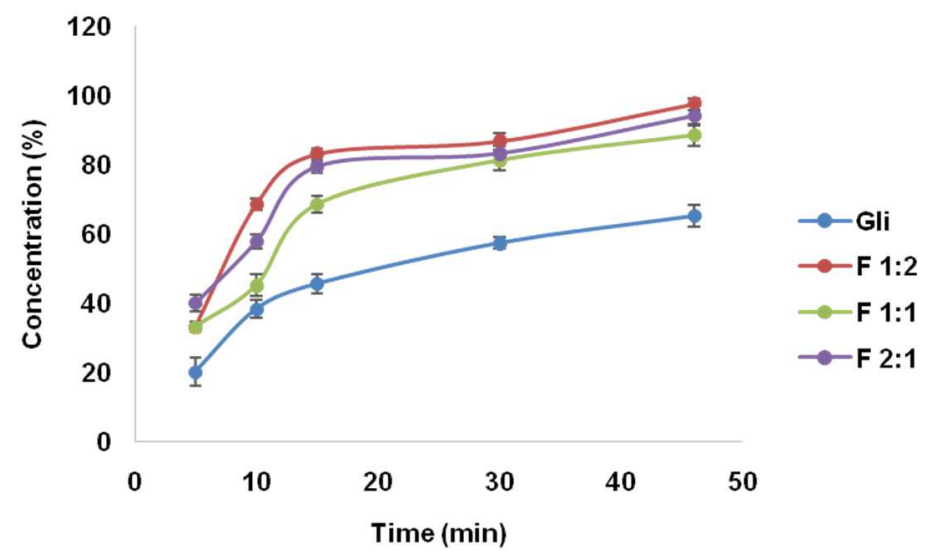

Fig. 6: In vitro drug release study of glibenclamide cocrystal tablet dosage form (All the values were calculated as mean \pm SD)

\section{In vitro dissolution study of tablet cocrystal}

The drug release of all cocrystal formulations were more than $80 \%$ at $60 \mathrm{~min}$. The tablets of 1:2 cocrystal was the highest drug release percentage among other tablets. However, cocrystallization glibenclamide was still potential because the tablet was made by direct compression method. Drug release percentage of pure glibenclamide tablet after $45 \mathrm{~min}$, cocrystal 1:1, 1:2, 2:1 were 65.32 $\%$; $94.06 \%$; $97.68 \%$; and $88.65 \%$ respectively.

\section{CONCLUSION}

The solubility and dissolution rate of GCM-SAC cocrystals increased significantly compared with pure GCM, especially for ratio of 1:2. The dissolution rate of cocrystal with ratio $1: 2$ increased by almost 91.9\% compared with pure GCM. Based on the FTIR analysis, it showed the shifting of characteristic bands of GCM in the spectrum and there was no chemical reaction in GCM cocrystal. In PXRD measurement, the new crystalline peak was detected in the crystal habit of cocrystal compared with pure GCM and coformer. The new single melting of GCM-SAC cocrystal also was detected in DSC measurement. The tablets of GCM-SAC cocrystal were successfully prepared by direct compression method which rapidly disintegrated (1 $\mathrm{min}$ ) and has higher dissolution compared with its pure form ( $32.36 \%$ greater than glibenclamide after $45 \mathrm{~min}$ ).

\section{AUTHORS CONTRIBUTIONS}

All the author have contributed equally

\section{CONFLICT OF INTERESTS}

Declared none

\section{REFERENCES}

1. Chaturvedi AK, Verma A. Solubility enhancement of poorly water-soluble drugs by solid dispersion. Int J Pharm Sci Res 2012;3:26-34.

2. Sopyan I, Fudholi A, Muchtaridi M, Puspita Sari I. Simvastatinnicotinamide co-crystal: design, preparation and preliminary characterization. Trop J Pharm Res 2017;16:297-303.

3. Ayoub M, Hasan A, El Nahas H, Ghazy FE. Enhancing oral bioavailability of carvedilol using solid dispersion technique. Int J Pharm Pharm Sci 2016;8:193-9.

4. Sola D, Rossi L, Schianca GPC, Maffioli P, Bigliocca M, Mella R, et al. Sulfonylureas and their use in clinical practice. Arch Med Sci AMS 2015;11:840-8.
5. Yalkowsky SH, Dannenfelser RM. Aquasol database of aqueous solubility. Coll Pharmacy, Univ Arizona, Tucson, AZ; 1992. p. 189.

6. Singh K, Kumar L, Prasad DN, Sharma S, Gupta GD. Fast dissolving tablet: a novel approach for the delivery of glibenclamide. Res Rev J Pharm Nanotechnol 2013;1:1-6.

7. Sajeev Kumar B, Saraswathi R, Venkates Kumar K, Jha SK, Venkates DP, Dhanaraj SA. Development and characterization of lecithin stabilized glibenclamide nanocrystals for enhanced solubility and drug delivery. Drug Delivery 2014;21:173-84.

8. Vaculikova E, Placha D, Pisarcik M, Jampilek J. Preparation of glibenclamide nanoparticles. $18^{\text {th }}$ Int. Electron. Conf Synth Org Chem; 2014. p. 1-30.

9. Shah SR, Parikh RH, Chavda JR, Sheth NR. Application of plackett-burman screening design for preparing glibenclamide nanoparticles for dissolution enhancement. Powder Technol 2013;235:405-11.

10. Dhillon N, Midha K, Nagpal M, Pahwa R. Formulation, optimization and characterization of solid dispersion of glibenclamide. Pharm Methods 2015;6:1-10.

11. Tabbakhian M, Hasanzadeh F, Tavakoli N, Jamshidian Z. Dissolution enhancement of glibenclamide by solid dispersion: solvent evaporation versus a supercritical fluid-based solventantisolvent technique. Res Pharm Sci 2014;9:337-50.

12. Saifee M, Zarekar S, Rao VU, Zaheer Z, Soni R, Burande S. Formulation and in vitro evaluation of solid-self-emulsifying drug delivery system (SEDDS) of glibenclamide. Am J Adv Drug Delivery 2013;1:323-40.

13. Azharshekoufeh L, Shokri J, Barzegar Jalali M, Javadzadeh Y. Liquigroud technique: a new concept for enhancing the dissolution rate of glibenclamide by a combination of liquisolid and co-grinding technologies. BioImpacts BI 2017;7:5-12.

14. Budiman A, Megantara S, Raraswati P, Qoriah T. Solid dosage form development of glibenclamide with increasing the solubility and dissolution rate using cocrystallization. Int J Appl Pharm 2018;10:181-6.

15. Budiman A, Megantara S, Apriliani A. Solid dosage form development of glibenclamide-aspartame cocrystal using the solvent evaporation method to increase the solubility of glibenclamide. Int J Appl Pharm 2019;11:150-4.

16. Siswandi S, Rusdiana T, Levita J. Virtual screening of co-formers for ketoprofen co-crystallization and the molecular properties of the co-crystal. J Appl Pharm Sci 2015;5:78-82.

17. Hickey MB, Peterson ML, Scoppettuolo LA, Morrisette SL, Vetter A, Guzmán $\mathrm{H}$, et al. Performance comparison of a co- 
crystal of carbamazepine with marketed product. Eur J Pharm Biopharm 2007;67:112-9.

18. Hiendrawan ST, Veriansyah BA, Widjojokusumo ED, Soewandhi SN, Wikarsa S, Tjandrawinata RR. Simultaneous cocrystallization and micronization of paracetamol-dipicolinic acid cocrystal by supercritical antisolvent (SAS). Int J Pharm Pharm Sci 2016;8:89-98.

19. Rajurkar VG, Sunil NA, Ghawate V. Tablet formulation and enhancement of aqueous solubility of efavirenz by solvent evaporation Co-Crystal technique. Med Chem 2015;2:S2-002.

20. Savjani JK, Pathak C. Improvement of physicochemical parameters of acyclovir using cocrystallization approach. Brazilian J Pharm Sci 2016;52:727-34.

21. Bhowmik D, Yadav R, Jayakar B, Kumar KPS. Formulation and evaluation of the oral tablets ibuprofen. Pharma Innov 2012;1:32-43.

22. Rajbhar P, Sahu AK, Gautam SS, Prasad RK, Singh V, Nair SK. Formulation and evaluation of clarithromycin co-crystals tablets dosage forms to enhance the bioavailability. Pharma Innov 2016;5:5-13.
23. Ansel HC, Popovich NG, Allen LV. Pharmaceutical dosage forms and drug delivery systems. Lippincott Williams and Wilkins; 1995.

24. Banerjee ND, Singh M. Formulation and evaluation of compression coated tablets of cefpodoxime proxetil. Int J Pharma Sci Res 2013;4:104-12.

25. Panzade P, Shendarkar G, Shaikh S, Rathi PB. Pharmaceutical cocrystal of piroxicam: design, formulation and evaluation. Adv Pharm Bull 2017;7:399-408.

26. Sopyan I, Fudholi A, Muchtaridi M, Sari IP. Co-crystallization: a tool to enhance the solubility and dissolution rate of simvastatin. J Young Pharm 2017;9:183-6.

27. Trask AV, Motherwell WS, Jones W. Solvent-drop grinding: green polymorph control of cocrystallization. Chem Comm 2004;7:890-1.

28. Basavoju S, Boström D, Velaga SP. Indomethacin-saccharin cocrystal: design, synthesis and preliminary pharmaceutical characterization. Pharm Res 2008;25:530-41.

29. Rodríguez Hornedo N, Nehm SJ, Jayasankar A. Cocrystals: design, properties and formation mechanisms. In: Swarbrick J. editor. Encycl. Pharm. Technol. Vol. 1. 3rd edition, New York: Informa Healthcare USA, Inc; 2007. p. 615-35. 